\title{
Desenvolvimento de identidade de marca para uma microempreendedora individual do ramo alimentício
}

\author{
Development of trademark \\ identity for an individual micro- \\ entrepreneur of the food industry
}

William Barboza Ximendes ${ }^{[1]}$

\begin{abstract}
Resumo: Este artigo apresenta os resultados do design de identidade de marca para uma Microempreendedora Individual (MEI) do ramo alimentício. O referencial teórico aborda o Microempreendedorismo Individual e a importância das marcas, ambos relacionados ao possível nicho de mercado da criação de marca para MEls, sobre o qual se observa que não há muito estudo. O método de pesquisa é bibliográfico de caráter qualitativo, com aplicação de um questionário a possíveis consumidores. Quanto ao projeto, foi aplicado o processo de Alina Wheeler, com ajustes para adequação ao contexto. Conclui-se que, assim como outras formas de Pessoa Jurídica, os MEls também precisam de projetos de marca, e que a metodologia aplicada cumpriu com sua função, visto que o projeto já contou com aprovação da cliente.
\end{abstract}

Palavras-chave: Marca. Microempreendedorismo. Metodologia Projetual. Branding. Identidade Visual.

Abstract: The objective of this present article introduces the results of research that started on the article of course conclusion. It was developed a visual identity and brand to a micro individual entrepreneur (MEI) of the food industry. This research in qualitative character approaching together to the referential theory two distinct 
topics: the micro individual entrepreneur and the importance of brands. Both have a direct relation to the niche market, which doesn't have many studies, the brand creation to MEI. The second proposal of this article, the practical project, it was chosen to present the four steps of project methodology of Alina Wheeler (2012), used to build the brand. It is considered that the article reached your goal, on show clearly the research as well as the results.

Keywords: Brand. Microempreendedor Individual. Project Methodology. Visual identity.

\section{INTRODUÇÃO}

Conforme os anos passam, o ser humano cada vez mais adquire o hábito de segmentar suas escolhas através das marcas, tendo em vista as mudanças nos conceitos de marca. De acordo com Strunck (2007), o ser humano cada vez mais é educado a consumir símbolos, imagens, marcas, e se apropriar da identidade de determinada marca para se encaixar em algum grupo ou acompanhar algo que é tendência. Isso enfatiza a importância do uso de uma identidade de marca, entretanto, não são todas as empresas, organizações ou empreendimentos que iniciam suas atividades com uma identidade de marca já definida e finalizada. É esse o caso, por exemplo, dos Microempreendedores Individuais (MEIs), uma modalidade de Pessoa Jurídica desenvolvida para viabilizar a formalização dos trabalhadores informais, com o objetivo de possibilitar que atuem dentro da legalidade. Tais empreendedores são tributados de forma diferente dos demais e atuam com limites em seu faturamento.

Ao entendermos que os Microempreendedores Individuais são enquadrados de forma diferenciada dos demais em algumas condições, e que alguns destes não possuem identidade de marca, percebe-se que há um nicho de mercado a ser explorado. Sendo assim, se faz necessária uma pesquisa em torno destes empreendedores, com ênfase em compreender melhor suas necessidades acerca do uso de identidade de marca. Nesse sentido, o objetivo delineado nesta pesquisa é desenvolver uma identidade de marca para um Microempreendedor Individual utilizando uma metodologia projetual que abarque as necessidades previstas no projeto. 
Antes de partir para o desenvolvimento da marca, foi necessária uma abordagem teórica, com o intuito de compreender aspectos importantes do Microempreendedorismo Individual e da importância das marcas. Através de uma metodologia de pesquisa bibliográfica qualitativa, concluiu-se que para a realização da parte prática do projeto, foi preciso aplicar uma metodologia projetual para a criação da marca. A mais adequada foi a metodologia de Alina Wheeler (2012), devido ao fato de ser ampla e possibilitar ajustes ao longo do projeto.

Dessa forma, o presente artigo apresenta o processo de desenvolvimento da marca Seu Sabor, abordando as etapas de criação, como a etapa de naming (criação de nomes), a etapa de desenvolvimento do logotipo, bem como a aplicação dessa identidade de marca em diversas peças, sendo as principais, o cartão de visitas, cardápios, e uniformes. Nesse sentido, se busca verificar a aplicabilidade da metodologia de Wheeler (2012) para a criação de uma identidade de marca para uma Microempreendedora Individual do ramo alimentício de Pelotas. A seguir, será apresentada a metodologia abordada no estudo.

\section{METODOLOGIA DE PESQUISA}

Este seção aborda a metodologia de pesquisa utilizada para a realização deste artigo. Optou-se por fazer uso de uma pesquisa qualitativa, que conforme Sampieri (2013), têm como característica compreender e examinar fenômenos através da coleta de dados narrativos, analisando as particularidades e experiências individuais, visando entender preferências, opiniões e motivações ocultas. A pesquisa feita no decorrer deste artigo pode ser considerada também uma pesquisa bibliográfica, que consiste em uma coleta de informações extraída a partir de textos, livros, artigos e demais documentos de caráter científico. Bem como, também possa ser considerada uma pesquisa exploratória, devido ao fato de que, há pouco material científico abordando especificamente os as- 
suntos que cercam os Microempreendedores Individuais, e a criação de identidade de marca para estes.

Para dar início ao desenvolvimento da marca, foram preciso diversas pesquisas antes de criar a identidade visual, uma parte desta pesquisa se tratava de buscar entender as preferências do consumidor final, a fim de gerar resultados que dessem direcionamentos para o projeto prático, foi elaborado um questionário, utilizando a ferramenta online "Editor Survey Monkey". Vale lembrar que este questionário foi divulgado através do Facebook pessoal do autor, portanto atingiu um número limitado de pessoas, em sua maioria jovens adultos que residem em Pelotas, portanto não obteve um número gigantesco de respostas.

O escopo do estudo foi abordar principalmente as questões acerca do desenvolvimento de marca, sendo assim, foram necessárias pesquisas específicas na área, visto que não há uma fórmula universal para a criação desta, que tende a variar de cliente para cliente. Na seção seguinte será apresentada uma breve contextualização acerca dos Microempreendedores Individuais.

\section{MICROEMPREENDEDOR INDIVIDUAL}

De acordo com o Portal do Empreendedor (2018), o Microempreendedor Individual (MEI) é um pequeno empresário individual que atua sob algumas restrições que o ME (microempresário) não tem. Apesar de ambos estarem enquadrados no Simples Nacional, o MEl recebe alguns privilégios em troca de algumas limitações. O limite de faturamento é uma das restrições que mais se diferencia das outras modalidades de empreendimento. Isso é visto como uma desvantagem, mas, diferente das demais modalidades, o MEI não paga imposto sobre o faturamento, o que pode ser considerado como uma vantagem. O Quadro 1 mostrado a seguir revela as principais diferenças entre o MEI e o ME. 


\section{Quadro 1 - Diferenças entre MEI e ME.}

MEI (microempreendedor

Individual)
ME (microempresa)

Pessoa Jurídica sem limites, pode ser sociedade, empresário individual, pode ser Eireli, e algumas modalidades de empresa.
Pessoa Jurídica com limitações, não pode participar como sócio, administrador ou titular de uma outra empresa, nem receber benefícios previdenciários.

Ter faturamento de no máximo R\$ $81.000,00$ por ano (R\$ 6.750,00 mês).

\begin{abstract}
A forma de tributação muda de acordo com o limite do faturamento, mas o limite é de 4.800.000,00 ano.
\end{abstract}

Paga somente o DAS (Documento de Arrecadação Simples Nacional), contendo alguns impostos em uma única guia.

Direito a benefícios da Previdência Social, como Auxílio Doença, Auxílio Acidente de Trabalho e Aposentadoria Somente por Idade.

Não paga impostos sobre faturamento.
Paga por impostos dependendo da modalidade em que está encaixado (se é comércio, prestação de serviços, entre muitos outros).

Direito a benefícios da Previdência Social tem que contribuir para o INSS sobre o valor retirado de Pró-Labore.

Paga percentuais de impostos sobre o valor faturado.

Fonte: adaptada do Portal do Empreendedor (2018), Bueno (2017).

Ao comparar um empreendedor com outro, pode-se notar que as diferenças entre estes são grandes no que diz respeito principalmente ao faturamento. Com isso, pode-se supor que suas atividades, prioridades e necessidades na administração de seu empreendimento podem ser totalmente diferentes das necessidades de outros clientes. No caso do MEl é preciso que seja desenvolvida uma marca com menores custos, mais rápida e que seja aplicável nos principais pontos de contato de acordo com as condições do cliente. Sendo assim este se torna um nicho interessante para se pensar, no que diz respeito à ao atendimento desses clientes, pensar nos serviços que devem ser prestados, e como devem ser con- 
duzidas as pesquisas para entender as necessidades desses clientes, no que diz respeito a criação de identidade de marca, considerando dificuldades como, dinheiro e tempo limitado para pesquisas aprofundadas. A seguir, será abordada a área voltada para o design, com ênfase na importância das marcas.

\section{A IMPORTÂNCIA DAS MARCAS}

Pode-se afirmar que nos dias de hoje, muitos produtos possuem especificações técnicas e padrões de qualidades bem semelhantes aos de seus concorrentes - de acordo com Pinho (1996), isso se dá devido aos grandes avanços tecnológicos e aos processos industriais de desenvolvimento dos produtos. Por conta disso, a marca acaba se tornando o elemento exclusivo de diferenciação da empresa no momento em que ela passa a atribuir valor ao produto com a intenção de se destacar dentre os produtos similares. Tanto que hoje as pessoas se vinculam a algumas marcas, o que se deve a motivos intangíveis que por vezes nem mesmo sabem identificar. Segundo Klein (2008), em meados dos anos 1980 e 1990, muitas empresas terceirizavam a fabricação de seus produtos e seus serviços, para investir mais em suas marcas, visto que o diferencial dos produtos estava cada vez mais se direcionando para as marcas. O que se percebe nos dias de hoje é que o interesse em investir na marca é algo que ainda cresce, sendo assim pode-se considerar que os MEls também tenham cada vez mais interesse em investir em suas marcas. A seguir será apresentado brevemente ao leitor o histórico da cliente, a qual já foi mencionada anteriormente como uma Microempreededora Individual do ramo alimentício de Pelotas.

\section{HISTÓRICO DO CLIENTE}

A fim de conhecer a cliente e o seu empreendimento, foi elaborada uma entrevista, na qual as perguntas buscavam compreender questões como: quem é, em que área atua, o que faz, como faz, quem são seus consumidores, histórico da 
marca, objetivos futuros relacionados à marca e como gostaria que sua marca fosse.

A partir desta entrevista feita com a cliente foram extraídas as seguintes informações; a cliente em questão é uma jovem do sexo feminino, residente da cidade de Pelotas (RS), formada no ensino médio, atualmente não se dedica totalmente ao negócio do ramo alimentício. A cliente formalizou-se recentemente, no fim de 2017, como Microempreendedora Individual no ramo alimentício. Seus produtos principais são as tortas doces, e sua renda mensal varia de $R \$ 1.150,00$ à $R \$ 1.400,00$, dependendo do volume de pedidos que consegue atender. Foi importante verificar a renda da cliente, visto que indiretamente a intenção do trabalho é criar uma marca, para um cliente que supostamente não possui vasto capital de investimento principalmente se falando em investimento de marca, considerando-se que há outros aspectos do negócio que também precisem de investimento. Na seguinte seção, será apresentada a prática projetual, na qual desenvolveu-se a identidade da marca.

\section{PRÁTICA PROJETUAL}

Nesta seção, será apresentado os resultados do processo de desenvolvimento da marca para a Microempreendedora Individual em questão, a partir da metodologia desenvolvida por Wheeler (2012).

\subsection{METODOLOGIA DE ALINA WHEELER}

A metodologia escolhida para desenvolver a identidade de marca para a Microempreendedora Individual, foi a de Alina Wheeler (2012), por explorar de forma abrangente os muitos aspectos, estratégias, e posicionamentos que uma marca pode conter. A Figura 1, a seguir, apresenta as cinco etapas para a construção de uma identidade de marca presentes na metodologia de Wheeler (2012). 
Pesquisa de mercado

Usabilidade

Auditoria de marketing

Auditoria da concorrência

Auditoria de linguagem

Relatório de auditoria

Fase 2

Esclarecimento da estratégia

\begin{tabular}{r|l} 
& Logotipo e assinatura visual \\
& Cores \\
Fase 3 & Mais cores \\
Design de & Tipografia \\
identidade & Som \\
& $\begin{array}{l}\text { Movimento } \\
\text { Aplicaçöes de teste } \\
\text { Apresentação }\end{array}$
\end{tabular}

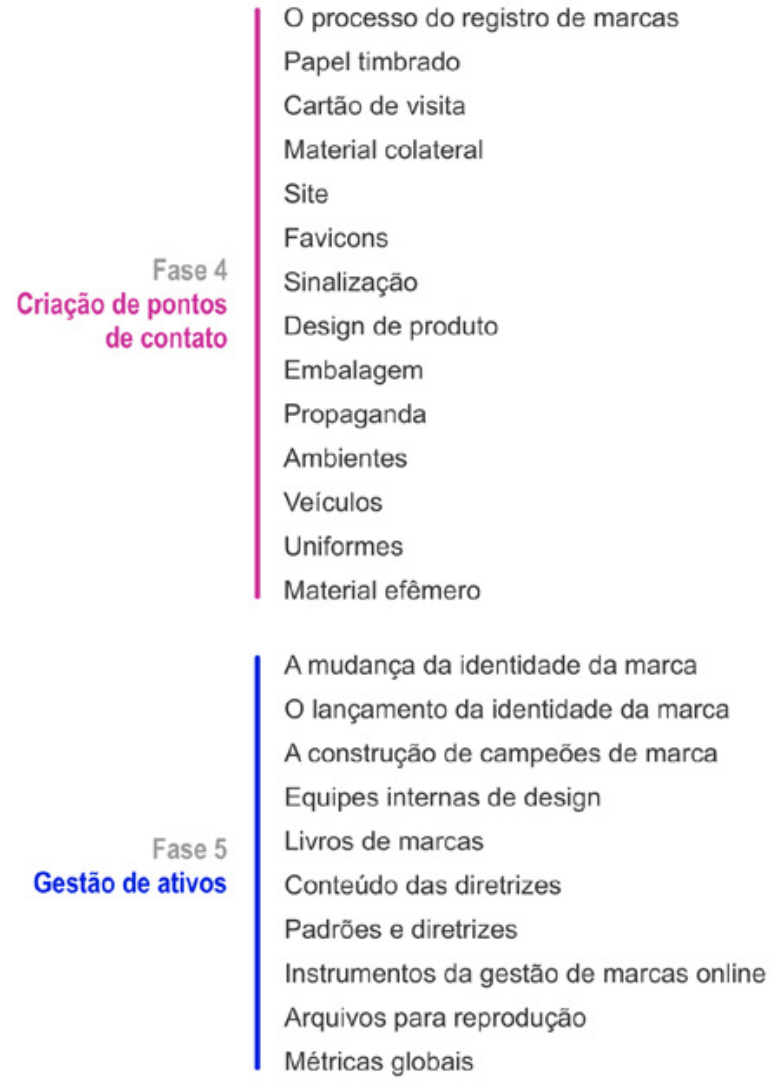

O processo do registro de marcas

Site

Design de produto

Embalagem

Propaganda

Ambientes

Veículos

Uniformes

A mudança da identidade da marca

O lançamento da identidade da marca

A construçāo de campeōes de marca

Equipes internas de design

Livros de marcas

Conteúdo das diretrizes

Arquivos para reprodução

Figura 1 - Metodologia de Alina Wheeler (2012). Fonte: adaptada de Wheeler (2012).

A seguir será apresentado a primeira etapa de condução da pesquisa, que dá início ao processo metodológico.

\subsection{CONDUÇÃO DA PESQUISA}

Ao dar início ao desenvolvimento da uma marca, antes de tudo é preciso fazer muitas pesquisas, com diferentes focos umas das outras, porém quando juntas se tem um entendimento melhor do que é preciso ser feito antes de colocar a "mão na massa", sem as pesquisas todas as estratégias para o negócio podem ser inúteis, e todo o caminho a seguir durante a construção da marca fica enevoado. Na metodologia da Wheeler (2012), esta etapa possui seis subetapas, porém ao serem analisadas as necessidades da cliente, foram previstas para o desenvolvimento da identidade apenas três destas subetapas sendo elas: A pesquisa de mercado, a auditoria da concorrência e o relatório de auditoria. 
Na pesquisa de mercado, como o próprio nome já diz foi feita uma pesquisa no mercado visando entender as necessidades e as preferências dos consumidores, para tal como já fora mencionado na metodologia de pesquisa, foi desenvolvido um questionário, em uma ferramenta de pesquisas online chamada "Editor Survey Monkey". Após concluir a pesquisa de mercado o próximo passo foi compreender a concorrência, na subetapa de auditoria da concorrência, esta pesquisa pode ser feita de diversas maneiras, através da internet, com entrevistas diretas com os concorrentes, ou até mesmo em visitas 'disfarçado de consumidor', de qualquer modo é fundamental conhecer o concorrente, para se ter ideia do que fazer e do que não se fazer também. Por fim o relatório da auditoria, que nada mais é do que um apanhado dos resultados da condução da pesquisa, por completo e resumido em um único documento, para que posteriormente fosse utilizada para brifar as estratégias da marca.

\subsection{ESCLARECIMENTO DA ESTRATÉGIA}

Esta etapa apesar de possuir poucas subetapas foi uma das mais importantes, pois foi nela que foram definidas as estratégias e o nome para a marca. Na subetapa de briefing da marca, foi desenvolvido um infográfico com todas as informações essenciais resumidas, de modo a facilitar o entendimento das características que a marca deveria contemplar. Já para a subetapa de criação de nome, foram necessárias reuniões com a cliente, nas quais foram feitas atividades de brainstorming, onde foram encontradas 167 palavras relacionadas ao ramo, e a partir destas foram criados 44 nomes para a cliente. Logo após foram feitas diversas filtragens até que o nome mais adequado fosse escolhido. Outro aspecto importante desta subetapa de criação de nomes, é a verificação da disponibilidade do nome, ou seja, se o nome já não está sendo utilizado por outros do ramo ou de fora do ramo também. 


\subsection{DESIGN DE IDENTIDADE}

Durante a execução desta etapa, apenas uma subetapa foi removida durante o processo de criação da marca, sendo essa denominada como "som", devido a cliente optar por uma estratégia mais simples e que não contempla o uso do som no material de sua marca.

Na primeira subetapa denominada como; logotipo e assinatura visual, como o próprio nome diz foram desenvolvidos o logotipo e a assinatura visual (fig. 2), porém há um detalhe importante que deve ser citado, durante a criação da assinatura visual, as pesquisas mostraram que era preciso que o logotipo fosse acompanhado da atividade fim, devido a área da cliente ser voltada especificamente para "doces e salgados", e não outros tipos de alimento, visto que o ramo alimentício é uma área com muitas vertentes.

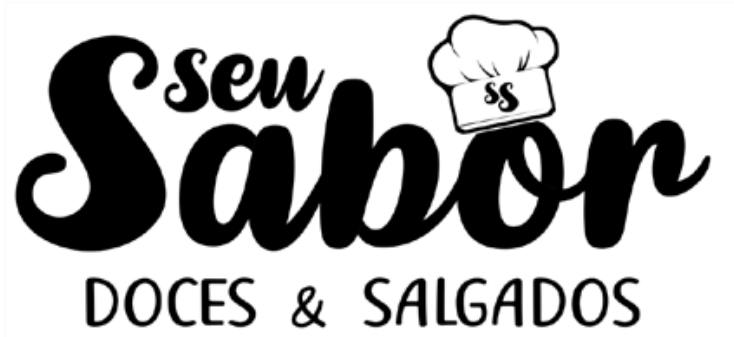

Assinatura prioritária

A atividade-fim (Doces \& Salgados) deve estar justaposta com o logotipo em todas aplicações, seja em peças próprias e materiais institucionais.

\section{Assinatura subsequente}

Considera-se viável o uso desta assinatura, a partir do momento em que a marca seja facilmente reconhecida pelos consumidores, e que a gama de serviços e produtos mude de modo que atividade-fim atual não abranja tais funções.

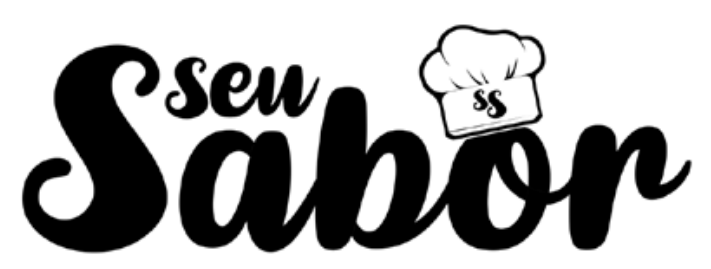

Figura 2 - Assinaturas da marca. Fonte: elaborada pelo autor.

A subetapa seguinte trata das cores ou cor que a marca fará uso, neste caso foi escolhido o tom magenta como a cor principal da marca tendo suas variações em magenta mais claro ou mais escuro, variando de acordo com o local da aplicação da marca, fig. 3. 

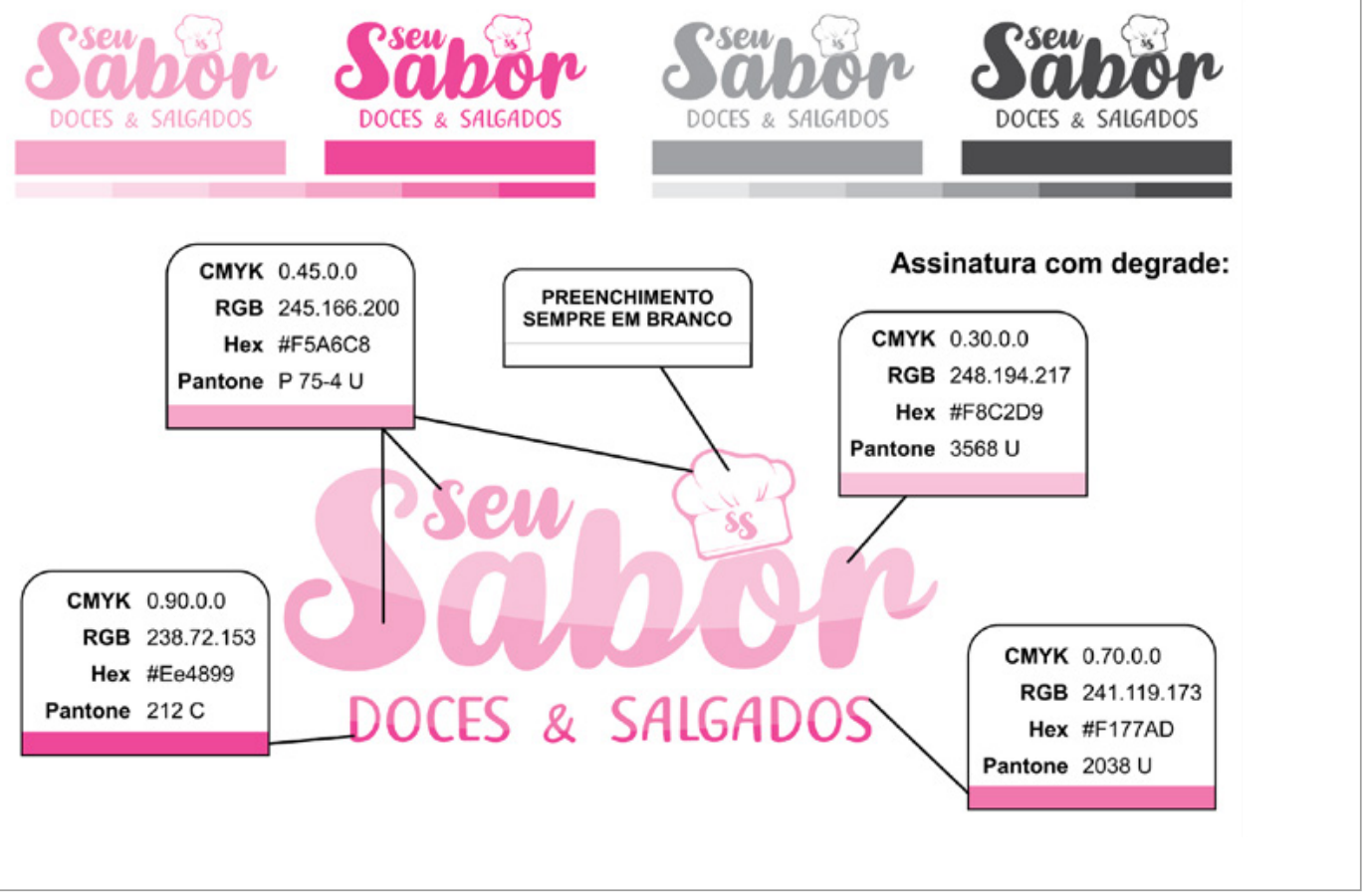

Figura 3 - Assinatura com cor. Fonte: elaborada pelo autor.

A terceira subetapa da criação foi a escolha tipográfica, esta etapa já teria sido iniciada antes no processo de criação da assinatura visual, para a criação do logotipo já havia se escolhido uma tipografia. Visando atender as características solicitadas no briefing, as tipografias escolhidas foram; para o logotipo a tipografia "Kathen", para a atividade fim "Well Bred", e para alguns textos em materiais institucionais da marca a tipografia "Dehasta Momentos".

Na subetapa de Movimentos, foi elaborada uma animação utilizando o logotipo da marca, e o símbolo que é um chapéu de cozinha que se movimenta até encaixar no logotipo. Foi criada com o intuito de ser uma forma divertida de apresentar a marca, e ser enviada até mesmo como GIF via redes sociais.

$\mathrm{Na}$ quinta subetapa referente às aplicações teste, foi desenvolvida uma padronagem para ser aplicada em diversas peças do material institucional da marca (fig. 4), ou até mesmo em brindes, tendo em vista que a intenção é a pregnância da identidade da marca, utilizando o chapéu como seu principal símbolo. E nesta etapa também onde foram desenvolvidos os protótipos para mostrar como a marca é aplicada, como; protótipo de caneca, uniforme, cartão de visita e sacola de compras. 


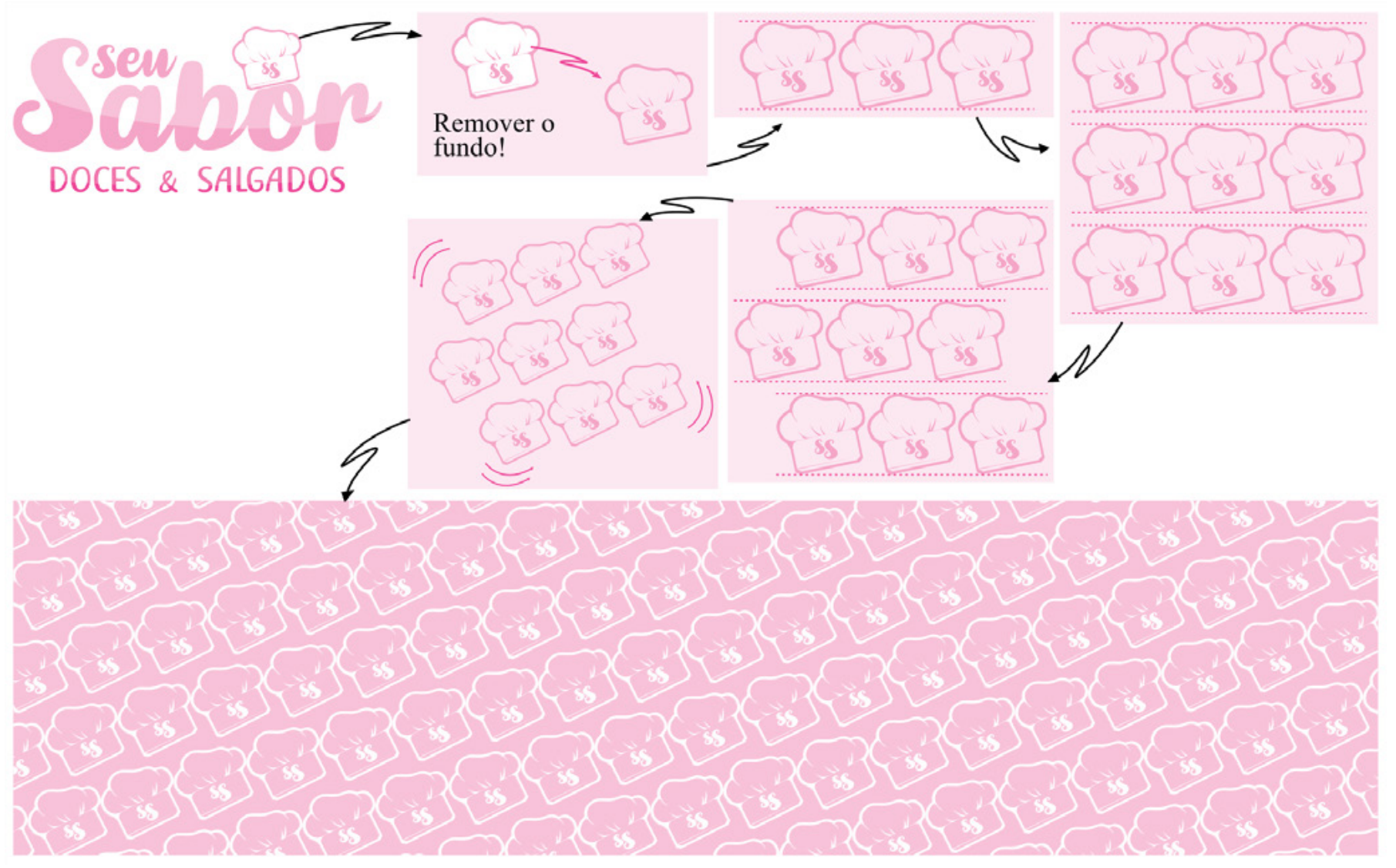

Por fim a última subetapa desta etapa foi a apresenFigura 4 - Criação da padronagem. Fonte: elaborada pelo autor. tação da identidade de marca, e dos protótipos desenvolvidos durante o processo de criação, considerando também as regras de aplicação da marca, como um dos materiais a ser apresentado.

\subsection{CRIAÇÃO DE PONTOS DE CONTATO}

Esta foi a última etapa do desenvolvimento da identidade marca deste estudo, porém ela só teve início logo após a cliente aprovar todo material mostrado anteriormente na subetapa de apresentação. Após a marca ser aprovada começou o desenvolvimento de diversos materiais da marca, os quais tinham como finalidade ser um ponto de contato entre o consumidor e a marca. O primeiro passo antes mesmo de criar o material é o registro da marca, no caso da cliente ela 
não o fez, mesmo tendo ciência dos riscos, devido a falta de dinheiro, visto que o processo de registro de marca pode ser considerado caro para muitos empreendedores.

O primeiro ponto de contato a ser criado foi o cartão de visitas (fig. 5), que dispensa apresentações, seguido dos “materiais colaterais", estes que contemplam os três cardápios digitais criados para serem veiculados principalmente através do WhatsApp, Instagram e Facebook (fig. 6 e 7). Também foi desenvolvido um avatar da marca, tanto para ser aplicado na foto de perfil da página oficial da marca no Facebook, tanto quanto para a foto de perfil do WhatsApp. Outro ponto de contato são as propagandas utilizadas muitas vezes em páginas da internet em formato de popup, nesse caso foi desenvolvida uma imagem para ser veiculada pensando neste formato. Foram desenvolvidos também diversos protótipos, entre eles um protótipo de embalagem, dois protótipos de placas de sinalização, três protótipos de uniformes (avental e chapéu de cozinha, mais uma camisa), e por fim mas não menos importante, dois protótipos de materiais efêmeros, sendo eles uma sacola de compras em tecido e uma caneca.

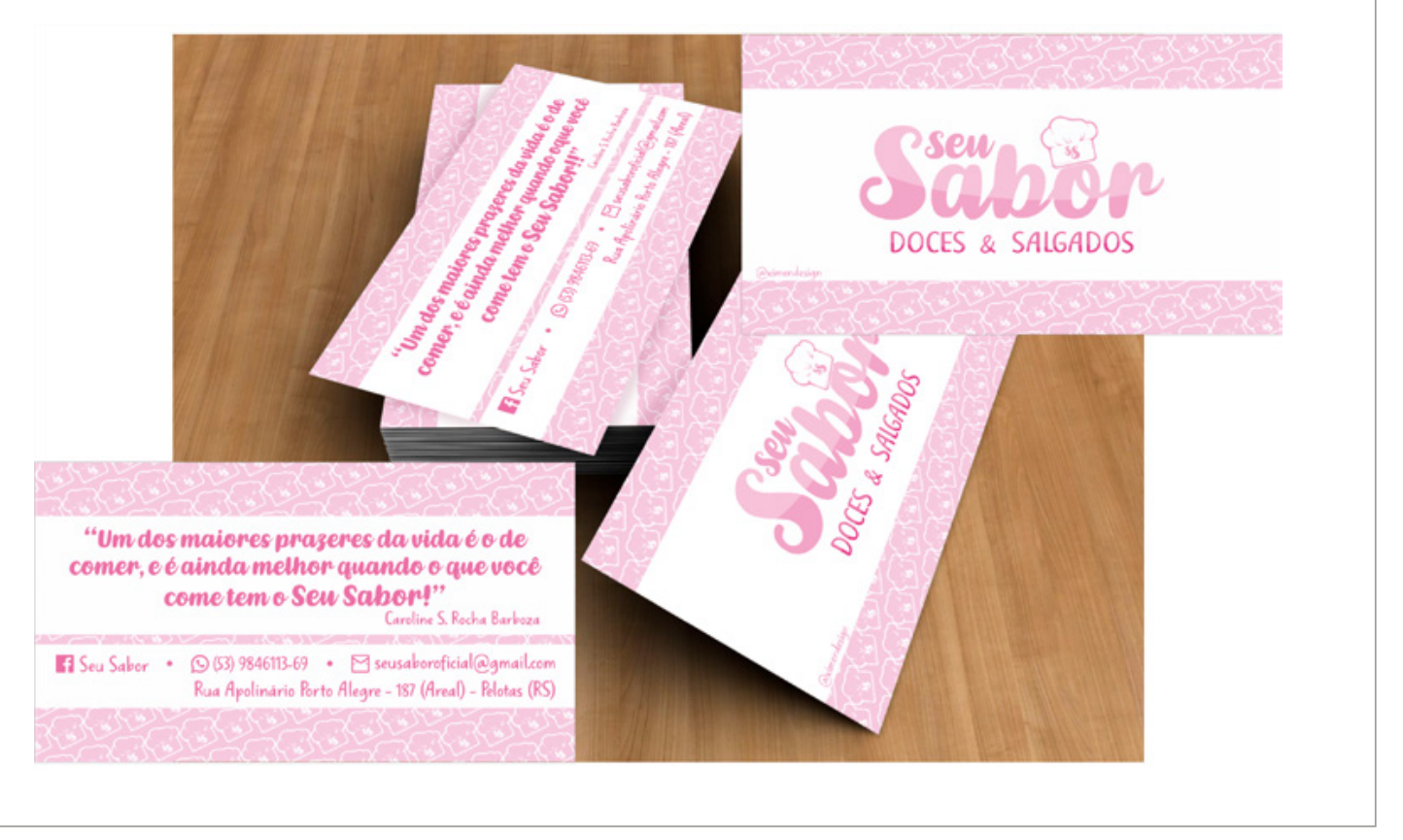

Figura 5 - Cartão de visitas. Fonte: elaborada pelo autor. 


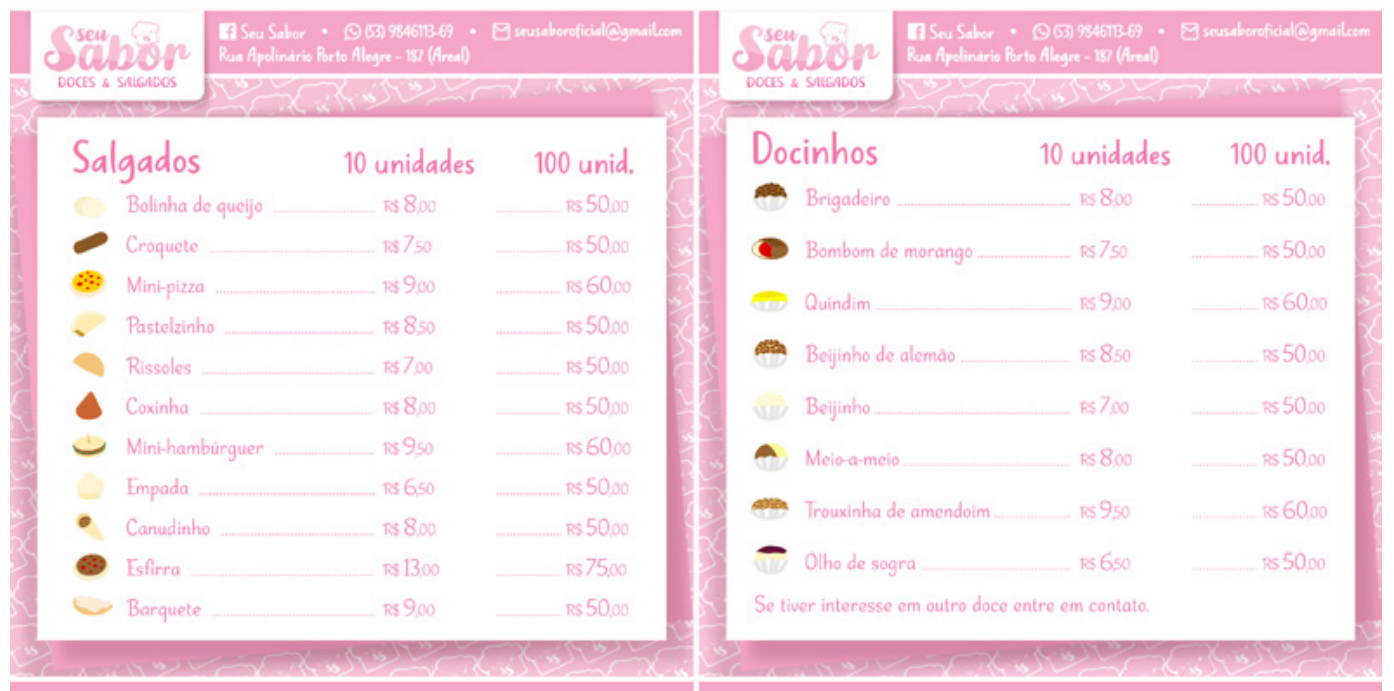

Figura 6 - Cardápios de doces e salgados. Fonte: elaborada pelo autor.

Figura 7 - Cardápio de tortas. Fonte: elaborada pelo autor.

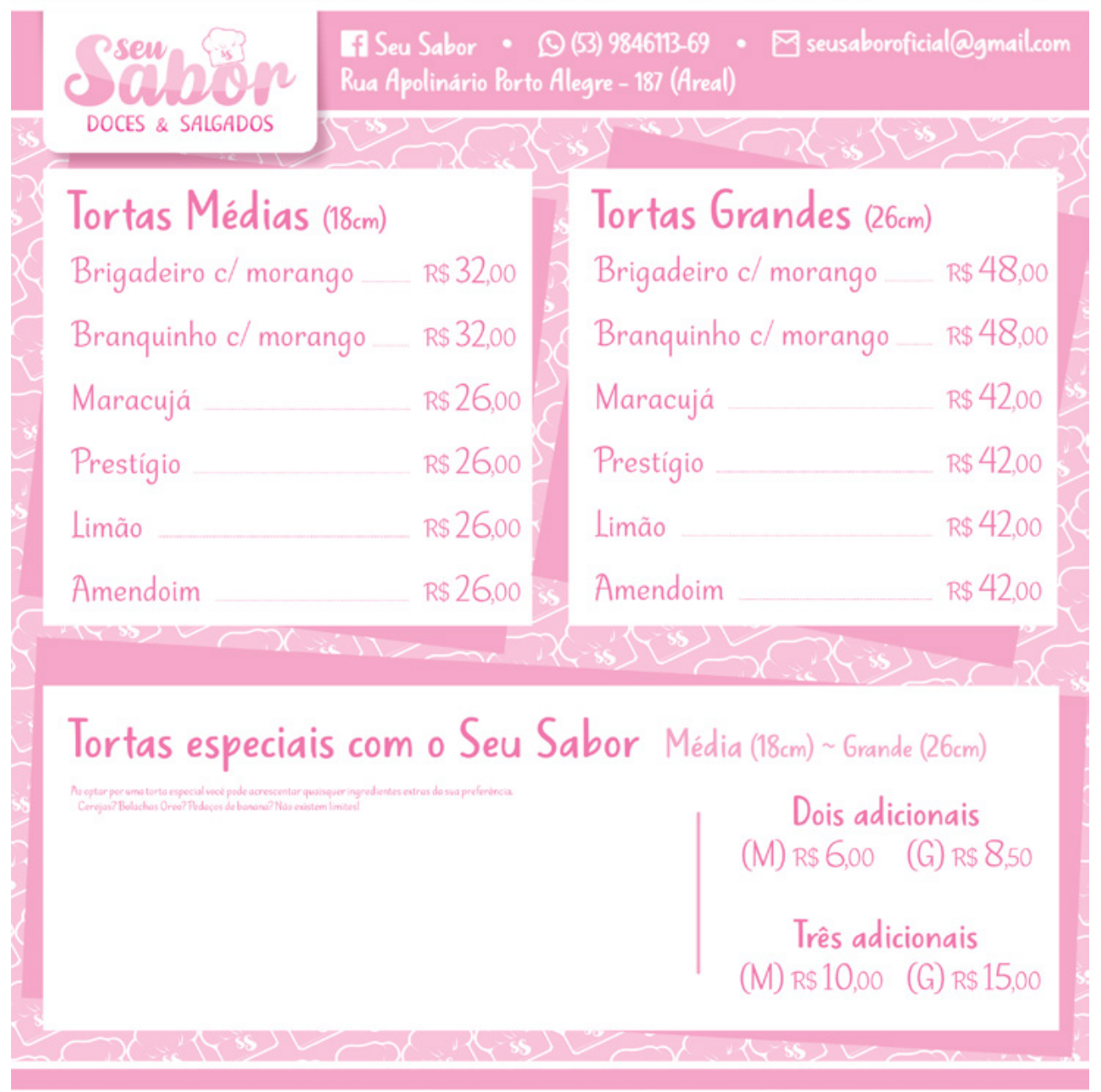




\section{CONSIDERAÇÕES FINAIS}

O presente artigo teve como objetivo apresentar o processo de desenvolvimento de uma identidade de marca para uma Microempreendedora Individual do ramo alimentício, e acredita-se que neste ponto o artigo cumpriu sua função. No que diz respeito aos resultados da pesquisa feita acerca da aplicabilidade da metodologia de Alina Wheeler (2012), para o desenvolvimento de uma identidade de marca para uma Microempreendedora Individual do ramo alimentício, concluiu-se que a metodologia aplicada foi efetiva, isso porque a identidade da marca é consistente em suas aplicações e coerente com as características e estratégias de posicionamento propostas durante o processo de criação da marca. Desta forma, considera-se que foram alcançados os resultados almejados pela cliente, considerando que foram aprovados todos os segmentos da identidade da marca até então. Pode-se apontar também que a metodologia não só atende às necessidades específicas de um projeto menor, como também aceita alterações em sua estrutura sem que seja comprometida sua eficácia metodológica, como a remoção de etapas, tanto de pesquisa quanto de criação de peças. Aceita também a adição de etapas, como por exemplo as peças gráficas não previstas na metodologia presentes na subetapa mídias digitais.

Ao concluir que este trabalho correspondeu adequadamente aos problemas explanados, é válido citar limitações acerca do estudo. A principal limitação está relacionada ao objeto de estudo: existe pouco material tratando acerca dos assuntos de marca para Microempreendedores Individuais, menos ainda quando se trata de Microempreendedores pelotenses do ramo alimentício. Outra limitação é o fato de este apenas ser um estudo com um cliente, dentre muitos outros clientes que poderiam ser objeto para pesquisas, a fim de testar metodologias projetuais, que atendam de forma apropriada esses clientes (MEls).

Ao considerar que os objetivos deste trabalho foram devidamente abordados e que foram alcançados os resul- 
tados esperados, pode-se afirmar que o trabalho contribuiu como um avanço nos estudos acerca da criação de marca para Microempreendedores Individuais, visto que essa é uma situação de projeto que, conforme se percebe tem sido frequente para os designers, qual seja a de atender clientes como os Microempreendedores Individuais, seja na questão de disponibilidade de investimento, quanto nas necessidades acerca das suas marcas.

\section{REFERÊNCIAS}

KLEIN, Naomi. Sem logo: A tirania das marcas

em um planeta vendido. Tradução de Ryta

Vinagre. $6^{\circ}$ ed. Rio de Janeiro: Record, 2008.

PINHO, J. Benedito. O poder das marcas.

São Paulo: Sammus Editorial, 1996.

PORTAL DO EMPREENDEDOR. Dúvidas frequentes.

Brasil: Portal do Empreendedor-Mei, 2018. Disponível

em: <http://www.portaldoempreendedor.gov.br/

duvidas-frequentes>. Acesso em: 3 out 2018.

SAMPIERI, Roberto Hernández; COLLADO, Carlos

Fernández; BAPTISTA LUCIO, María Del Pilar.

Metodologia de pesquisa. Tradução Daisy Vaz

de Moraes. $5^{\circ}$ ed. Porto Alegre: Penso, 2013.

STRUNCK, Gilberto Luiz. Como criar identidades

visuais para marcas de sucesso: Um guia sobre o

marketing das marcas e como representar graficamente

seus valores. Rio de Janeiro: Rio Books, 2007.

WHEELER, Alina. Design de Identidade da Marca: Guia essencial para toda a equipe de gestão de marcas. Tradução

Francisco A. da Costa. 3ed. Porto Alegre: Bookman, 2012. 